\title{
Floridoside Extracted from the Red Alga Mastocarpus stellatus Is a Potent Activator of the Classical Complement Pathway
}

\author{
Anthony Courtois ${ }^{1,2}$, Christelle Simon-Colin ${ }^{1}$, Claire Boisset ${ }^{1}$, Christian Berthou ${ }^{2}$, Eric \\ Deslandes ${ }^{3}$, Jean Guézennec ${ }^{1}$ and Anne Bordron ${ }^{2, *}$
}

1 Biotechnologies and Marine Molecules laboratory, IFREMER - Brest Center, Technopôle BrestIroise, France; E-mails: Anthony.Courtois@ifremer.fr(A.C.); Christelle.Simon.Colin@ifremer.fr (C.S.-C); Claire.Boisset@ifremer.fr (C.B.); Jean.Guezennec@ifremer.fr (J.G.)

2 Cellular Therapy and Immunobiology of Cancer laboratory, EA2216, Brest University Hospital, France; E-mails: christianberthou@wanadoo.fr (C.B.); Anne.bordron@univ-brest.fr (A.B.)

3 Ecophysiology and Biotechnology of Halophytes and marine Algae laboratory (LEBHAM), European Institute of Marine Studies, University of Western Brittany, Technopôle de Brest-Iroise E-mail: eric.deslandes@univ-brest.fr (E.D.)

* Author to whom correspondence should be addressed. Tel., +33-298-22-30-28; Fax, +33-298-22-3028; E-mail: Anne.bordron@univ-brest.fr

Received: 7 December 2007 / Accepted: 5 June 2008 / Published: 10 July 2008

\begin{abstract}
Many biological properties of algae have been found to have useful applications in human health, particularly in the fields of oncology and immunology. Floridoside, extracted from the red alga Mastocarpus stellatus, has a structure similar to the xenoantigen Gal alpha 1-3 Gal. This xenoantigen has been described to induce a high immune response in human xenografts and is mediated by natural anti-gal antibodies that activate the classical complement pathway. Based on this property, we analyzed the potential activities of floridoside on the immune system. We demonstrated that floridoside activates a complement cascade via the classical complement pathway, through the recruitment and activation of natural IgM. This algal molecule could represent an important step in the development of a potent new anticomplementary agent for use in therapeutic complement depletion.
\end{abstract}

Keywords: Alpha-galactosyl glycerol, marine algae, immunomodulation, complement system 


\section{Introduction}

Molecules isolated from marine organisms have already been reported to possess antitumoral activities. However, in comparison to sponges, mollusks or ascidians, algae have been at the origin of only few studies focused on oncological or immunological applications. In fact, biological properties of oncological or immunological interest have been demonstrated in 140 species of algae, but molecules from only three species of red algae are currently in preclinical trials. Previous studies have often been limited to preliminary screening without collaboration with pharmaceutical laboratories for developing new drugs. Nevertheless, the discovery, isolation and characterization of new bioactive marine molecules (especially terpenes, polysaccharides, alkaloids, halogenated compounds, phenolic compounds, etc.) from different types of marine algae should generate many productive studies in terms of potentially useful biological properties in the near future.

Floridoside is a neutral heteroside found in many red algae originally isolated from the Rhodophyceae Rhodymenia palmate or Mastocarpus stellatus. Produced directly from photosynthesis, floridoside constitutes an important soluble carbon reserve readily available according to cellular needs $[1,2]$ and, in aqueous solution, it behaves as an osmoregulator involved in the resistance of the algal cell wall to changes in external salinity. The molecular structure of floridosides was first established by Putman and Hassid [3] in 1954, who characterized it as a 2-O- $\alpha-\mathrm{D}-$ galactopyranosylglycerol. The terminal Gal $\alpha(1-3)$ structure of this molecule is similar to the linear B trisaccharide (Gal $\alpha(1-3)$ Gal $\beta(1-4)$ GlcNAc) named Gal xenoantigen or Galili epitope [4]. This antigen is responsible for the human xenograft rejection due to the presence of natural anti-gal antibodies. These antibodies are mainly immunoglobulins of type $M$ and $G(\operatorname{IgM}$ and $\operatorname{IgG}$ ) with a strong capacity to activate the classical complement pathway, through recruitment and activation of the C1q protein that ultimately leads, to cell destruction by forming the membrane attack complex (MAC).

Because of the structural similarity between floridoside and Galili epitope, we were interested in evaluating the activity of the floridoside on the complement system. First, floridoside was extracted from the red alga Mastocarpus stellatus, purified and characterized. Then, its activity on the complement system was tested using hemolytic assays as well as in a solid-phase Enzyme-Linked Immunosorbent Assay (ELISA) system and, finally, compared to Galili epitope activity. The results obtained with floridoside are presented here and the potential biological applications of this molecule are discussed.

\section{Results and Discussion}

\subsection{Extraction, purification and chemical structure}

The floridoside was extracted from the red alga Mastocarpus stellatus with a mixture of $\mathrm{MeOH}$ $\mathrm{CHCl}_{3}-\mathrm{H}_{2} \mathrm{O}$ and was purified from the hydroalcoholic fraction. The chemical structure was determined as $\mathrm{C}_{9} \mathrm{H}_{18} \mathrm{O}_{8}$ (with a molecular weight of $253 \mathrm{~g} \cdot \mathrm{mol}^{-1}$ ) on the basis of NMR and GC/MS analysis. This structure was in complete agreement with those published by Simon-Colin et al. [1,2]. Based on these data, floridoside was confirmed as ((2-O- $\alpha$-D-galactopyranosyl) $1 \rightarrow 2$ ' (glycerol)) (Figure1). 
Figure 1. Chemical structure of floridoside.

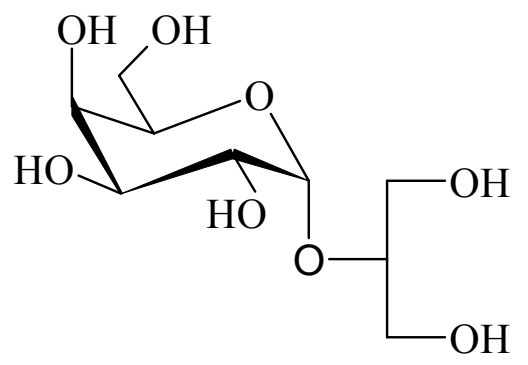

\subsection{Biological activities of floridoside}

The complement system is a major effector of humoral immunity involved in host defense. It is a complex system comprised of at least 30 serum proteins, such as $\mathrm{C} 4$ or $\mathrm{C} 2$ molecules, which interact in a cascade of activation. Many of the early components are serine proteases, which activate each other sequentially. The activation cascade results in the formation of MAC that perforates the plasma membrane of the target cell $[5,6]$. In order to determine the role of floridoside on the complement system, hemolytic assays were analyzed after contact with sensitized sheep erythrocytes.

The effect of different floridoside concentrations was determined in vitro using normal human serum (NHS) as the complement source. As a first approach, we validated the experimental model by testing different concentrations of aggregated IgG. Aggregated IgG is known to be a powerful activator of the complement system and was used as a positive control for the reaction [7]. The capacity of the NHS serum to restore the hemolytic activity of a serum deficient in one protein of the complement system was measured. First, the $\mathrm{CH}_{50}$ representing the NHS dilution that leads to $50 \%$ lysis was determined. In our experiments, $\mathrm{CH}_{50}$ was reached at a 1:100 dilution. Then, increasing amounts of aggregated $\mathrm{IgG}(0-100 \mu \mathrm{g})$ in $\mathrm{CH}_{50}$ NHS conditions were incubated with a C2-deficient serum and the complement activation was determined by measuring the amount of released hemoglobin. The rate of activation by aggregated $\mathrm{IgG}$ in veronal buffer $\left(\mathrm{VBS}^{2+}\right)$ increased very rapidly with amounts of $\mathrm{IgG}$ and reached a plateau corresponding to $80 \%$ (data not shown). These results confirm that aggregated IgG is a very efficient activator. The same experimental conditions were applied to floridoside. Increasing amounts of floridoside $(0-100 \mu \mathrm{g})$ in $\mathrm{CH}_{50}$ NHS conditions were incubated with a $\mathrm{C} 4$-deficient or $\mathrm{C} 2$-deficient serum and complement activation was determined by measuring the amount of released hemoglobin. As shown in Figure 2A, the rate of activation by floridoside in veronal buffer $\left(\mathrm{VBS}^{2+}\right)$ increased very rapidly with amounts of floridoside and reached a plateau corresponding to $100 \%$. These results indicate that floridoside was very efficient in activating the complement system, with a rate of 50\% (AC 50) at $1.5 \mu \mathrm{g}$ and $2 \mu \mathrm{g}$ using $\mathrm{C} 2-$ and C4-deficient serum, respectively (Figure 2B).

Complement activation can be initiated by three pathways, all of them generating homologous variants of the protease $\mathrm{C} 3$-convertase. Typically, the classical complement pathway requires antibodies for activation (specific immune response), while the alternative and the mannose-binding lectin (MBL) pathways can be activated either by $\mathrm{C} 3$ hydrolysis or by antigens and does not require the presence of antibodies (non-specific immune response) (Figure 3). The C4 and C2 proteins used in our test conditions are specific to both classical and MBL pathways. In order to identify which 
particular pathway of the complement system was activated by floridoside, additional assays were carried out using a human C1q-deficient serum specific to the classical pathway along with varying amounts of floridoside $(10,50$ and $100 \mu \mathrm{g})$. The results, presented in the Figure 4, demonstrated that activation occurred using the C1q-deficient serum, indicating that floridoside was specifically involved in the classical pathway.

Figure 2. Floridoside activation of the complement system. Activation was measured by the capacity of NHS incubated with various quantities of floridoside to restore serum deficient or depleted in complement proteins $\mathrm{C} 4$ and $\mathrm{C} 2$, respectively. (A) Activation using a wide range of floridoside concentrations. (B) Close-up of (A) for floridoside quantities $\leq 10 \mu \mathrm{g}$. Each point represents the mean $( \pm \mathrm{SE})$ determined from three to six trials.

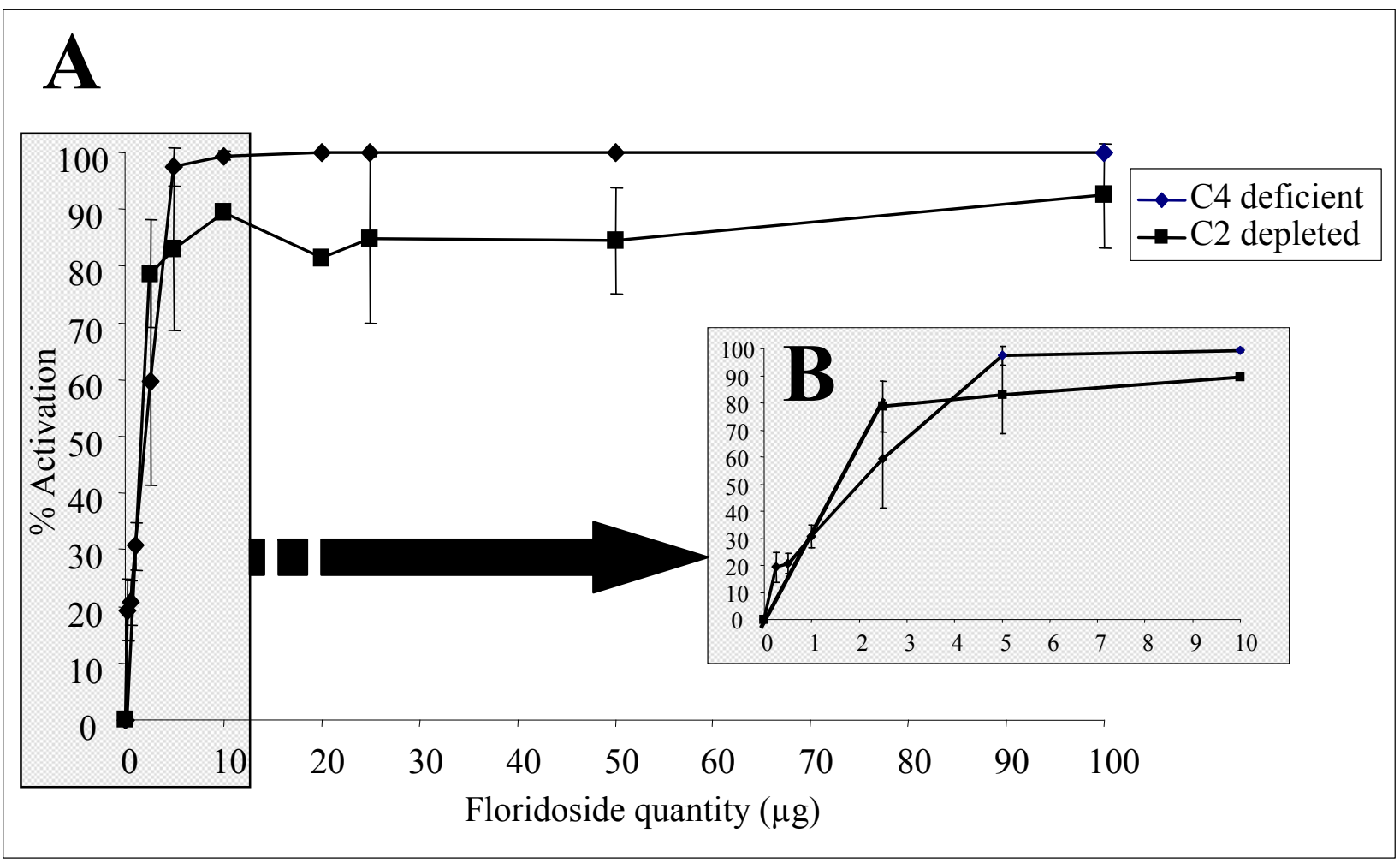

In order to confirm that the classical pathway was specifically activated by floridoside, the production of $\mathrm{C} 4 \mathrm{~d}$ protein was measured by ELISA assays. Classical pathway activation is triggered upon the binding of the $\mathrm{Clq}$ component to IgG- or IgM-containing immune complexes or other activating molecules. The binding of $\mathrm{Clq}$ to one of these activators results in the conversion of the $\mathrm{C} 1$ complex to an active proteolytic enzyme cleaving $\mathrm{C} 4$ to $\mathrm{C} 4 \mathrm{a}$ and $\mathrm{C} 4 \mathrm{~b}$. As an anaphylatoxin, $\mathrm{C} 4 \mathrm{a}$ has a short half-life and is bound by cells possessing the appropriate receptors. $\mathrm{C} 4 \mathrm{~b}$ mediates opsonization of target cells and can participate in the formation of the classical pathway $\mathrm{C} 3$-convertase. $\mathrm{C} 4 \mathrm{~b}$ is rapidly cleaved by factor I, generating the fragments $\mathrm{C} 4 \mathrm{c}$ and $\mathrm{C} 4 \mathrm{~d}$. In our experiment, NHS was incubated with various amounts of floridoside $(5 \mu \mathrm{g}, 50 \mu \mathrm{g}$ and $100 \mu \mathrm{g})$ and the $\mathrm{C} 4 \mathrm{~d}$ produced by the complement activation was determined using the Quidel ${ }^{\circledR}$ C4d EIA Kit. Our results showed that floridoside induced the production of $\mathrm{C} 4 \mathrm{~d}$ in a dosage-dependent way, confirming that it activates the complement system through the classical pathway (Figure 5). 
Figure 3. The three main pathways that activate the complement system.

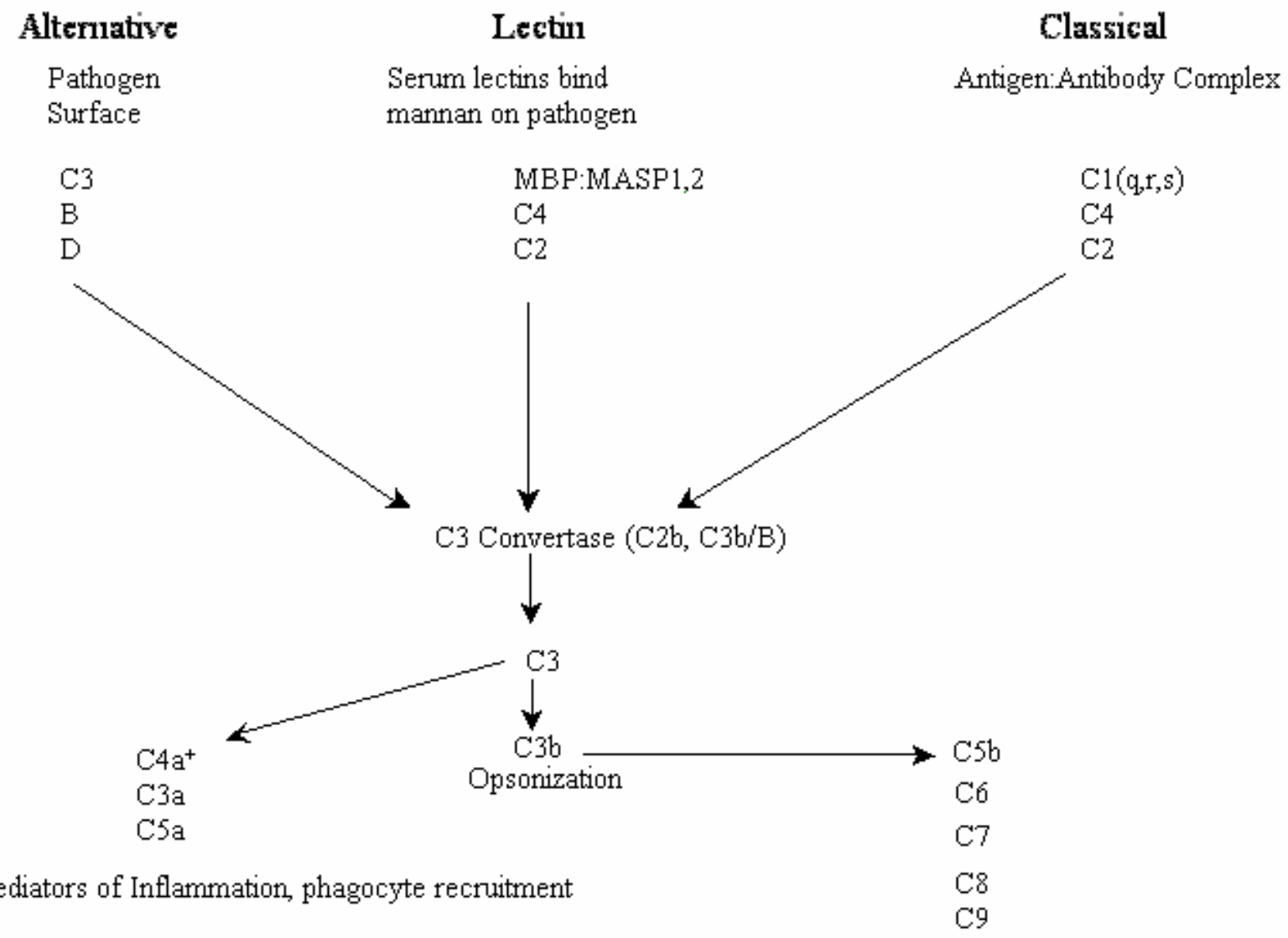

Membrane attack complex, lysis of cells

Figure 4. Quantity-response curves of floridoside activation of the complement system. Activation was measured by the capacity of NHS incubated with various quantities of floridoside on restoring serum deficient in complement proteins (C1q). Each point represents the mean $( \pm \mathrm{SE})$ determined from three to six trials.

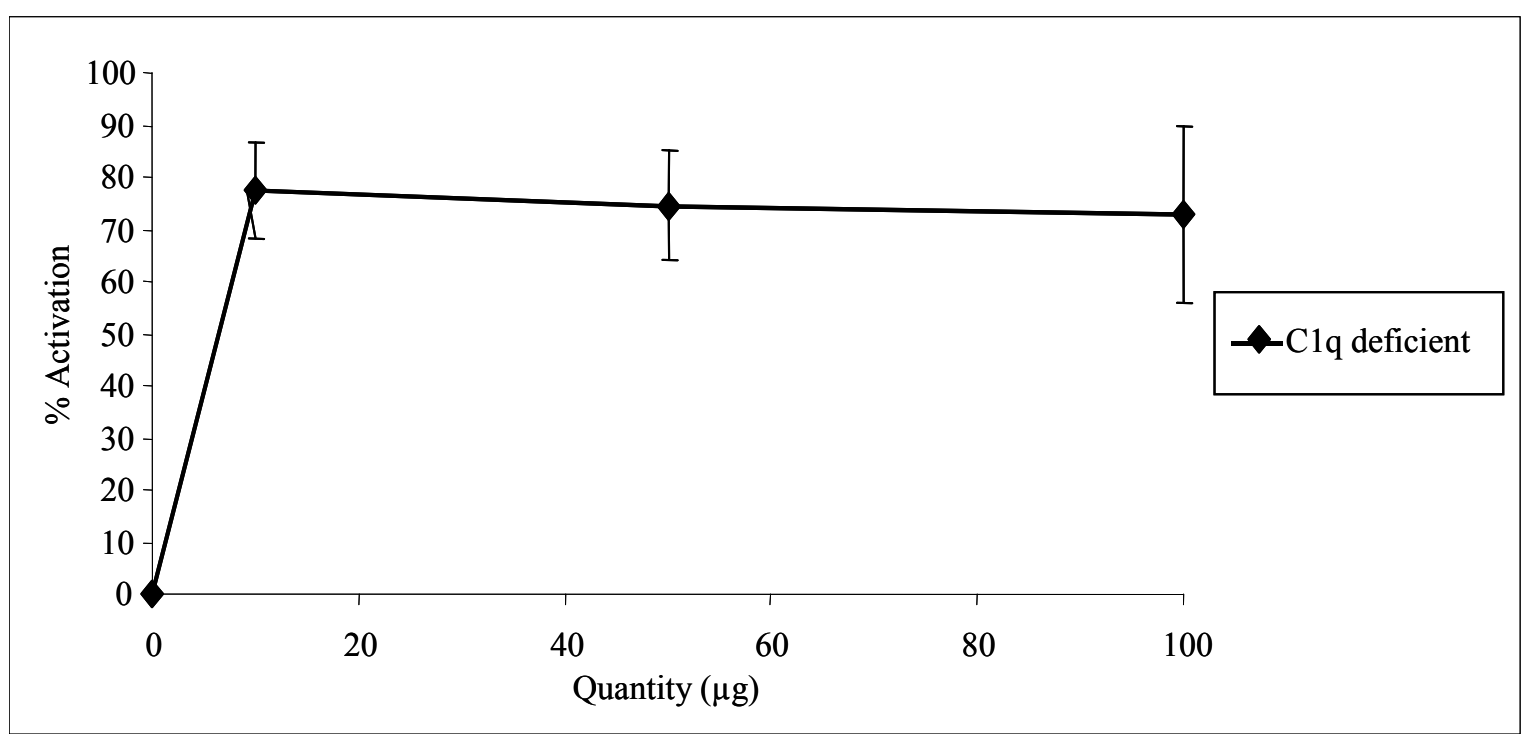


Figure 5. C4d production in NHS incubated with floridoside determined by ELISA assays. Each point represents the mean determined from four trials.

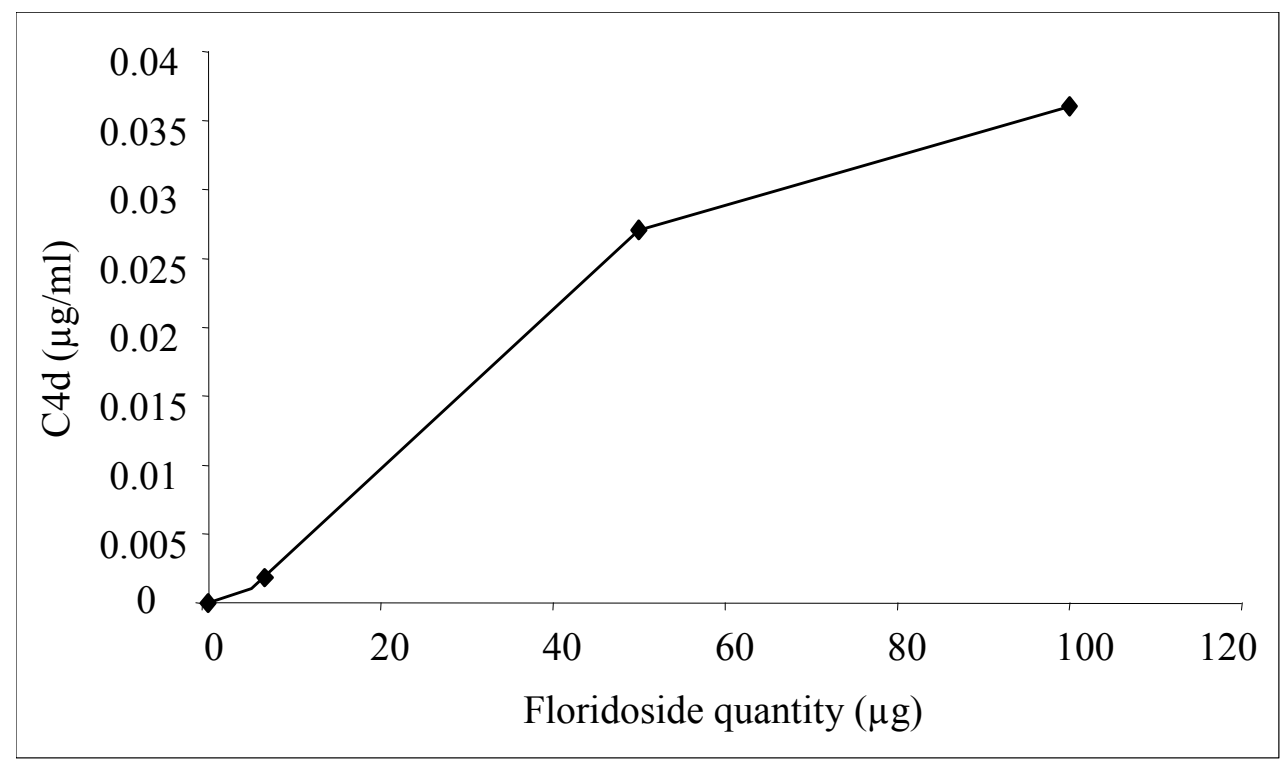

Moreover, the classical pathway can be activated via two main mechanisms: (1) a direct activation of the C1q protein or (2) the natural recruitment of IgM able to activate the system. In order to determine the mechanism of activation, we evaluated the activation of the complement system in a serum obtained from umbilical cord blood (US) in which IgM are lacking [8]. Various quantities of floridoside ( $5 \mu \mathrm{g}, 10 \mu \mathrm{g}$ and $50 \mu \mathrm{g}$ ) were incubated with US and the complement system activation was evaluated by hemolytic assays using human serum deficient in the $\mathrm{C} 2$ protein. Results were compared to those obtained using NHS (Figure 6). Floridoside activation using US was significantly weaker than the one measured using NHS under the same experimental conditions. This result indicates that activation of the classical complement pathway by floridoside is mediated by natural IgM. The observed residual activity was most likely due to natural IgG directed against floridoside.

We can conclude that floridoside constitutes a potent activator of the classical complement pathway and this activation seems to be mediated by the recruitment and the activation of natural IgM directed against this molecule. Floridoside possesses an alpha-Gal terminal structure similar to the Galili epitope. As noted previously, this $\alpha$-galactosyl core is absent in human cells but is naturally expressed-with millions of epitopes per cell-on glycolipids and glycoproteins in non-primate mammals, prosimians (e.g. lemurs) and New World monkeys (monkeys of South and Central America) $[4,9,10]$. This epitope is responsible for xenograft rejection, via the complement system, by recruiting and activating natural IgM and IgG [11]. Anti-Gal IgM and IgG molecules are the most abundant natural antibodies in humans, constituting about $1 \%$ of the total immunoglobulins present in serum [9, $12,13,14]$. Given the structural similarity of floridoside and this immunogenic epitope, we hypothesized that the activation of the complement system by floridoside could be due to these natural anti-Gal antibodies. We performed experiments to compare the capacity of these two molecules to activate the classical pathway. Hemolytic assays were thus carried out by measuring the restoration of a C4-deficient serum with NHS incubated by various amount of floridoside or Galili epitope (1, 2, 4, 10, 20, $40 \mu \mathrm{mol})$. The results, presented in Figure 7, indicate that, unlike floridoside, the Galili epitope 
is not able to activate the complement system. This confirms that the floridoside molecule is able to activate the complement system through its recognition by natural IgM. Furthermore, the main condition for the initiation of complement activation by $\alpha$-Gal epitope is its fixation to the cell surface. This hypothesis is confirmed by the use of this epitope alone in therapy and by its capacity to interact with natural immunoglobulins ( $\operatorname{IgM}$ or $\mathrm{IgG}$ ) without triggering an immune response [15]. A difference in epitope orientation and accessibility (free or linked) could explain why the Galili epitope in this assay did not induce the expected results [4, 9]. Using gas chromatography coupled with mass spectrometry, we verified that floridoside was not aggregated in solution since aggregates could have conferred the observed biological activity (data not shown). This study clearly demonstrated that activation of the complement system by floridoside is undoubtedly due to natural $\operatorname{IgM}$ directed against this molecule. However, we do not yet have direct evidence that these antibodies are natural anti-Galili epitope IgM. Additional studies are required to determine which type of $\operatorname{IgM}$ actually interacts with the floridoside and confers the capacity to activate the complement system.

Figure 6. Evaluation of floridoside complement activation using NHS and umbilical serum (US). Experiments were performed using serum deficient in the $\mathrm{C} 4$ protein. Each point represents four trials analyzed using the Student's $t$-test and ANOVA. The asterisk (*) represents significant differences $(p<0.05)$ between NHS and US at a given quantity.

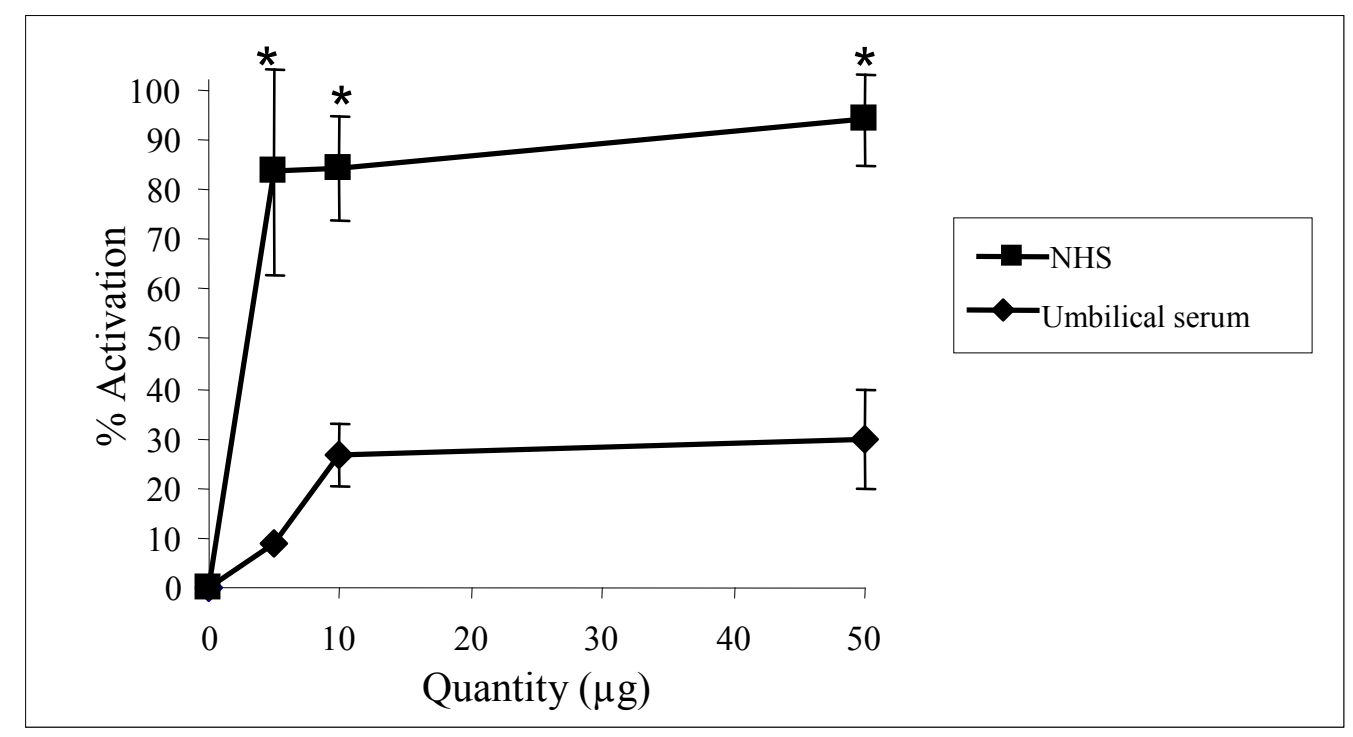

In summary, natural floridoside was purified from the red alga Mastocarpus stellatus and identified as a (2-O- $\alpha$-D-galactopyranosyl) $1 \rightarrow 2$ ' (glycerol)). Biological results obtained in this study strongly indicate a close relationship between floridoside and innate immunity. This is the first time that the molecule of floridoside has been described as an activator of the complement system, particularly via the classical pathway. This activation is probably due to natural IgM and our results confirm that immune complexes are formed in solution with floridoside. Substantial efforts are being devoted to develop new drugs for complement inhibition [16]. However, these experimental drugs aim to inhibit complement activation by rapidly consuming enzymatic cascade proteins or by depleting them [17]. Floridoside, as a new natural molecule, may represent a promising new anticomplementary agent. Furthermore, the complement system plays an important role in the immunotherapeutic action of 
monoclonal antibodies [18], particularly in the treatment of cancer. In combination with monoclonal antibodies, floridoside could be used to enhance the biological activity of new targeted therapies and may thereby be a potentially useful drug for cancer therapy.

Figure 7. Comparison between floridoside and $\alpha$-Gal epitope in their capacity to activate the complement system. This experiment was performed using serum deficient in the $\mathrm{C} 4$ protein. Each point represents four trials analyzed using Student's $t$-test and ANOVA. The asterisk $(*)$ represents significant differences $(\mathrm{p}<0.05)$ between floridoside and $\alpha$-Gal epitope at a given concentration.

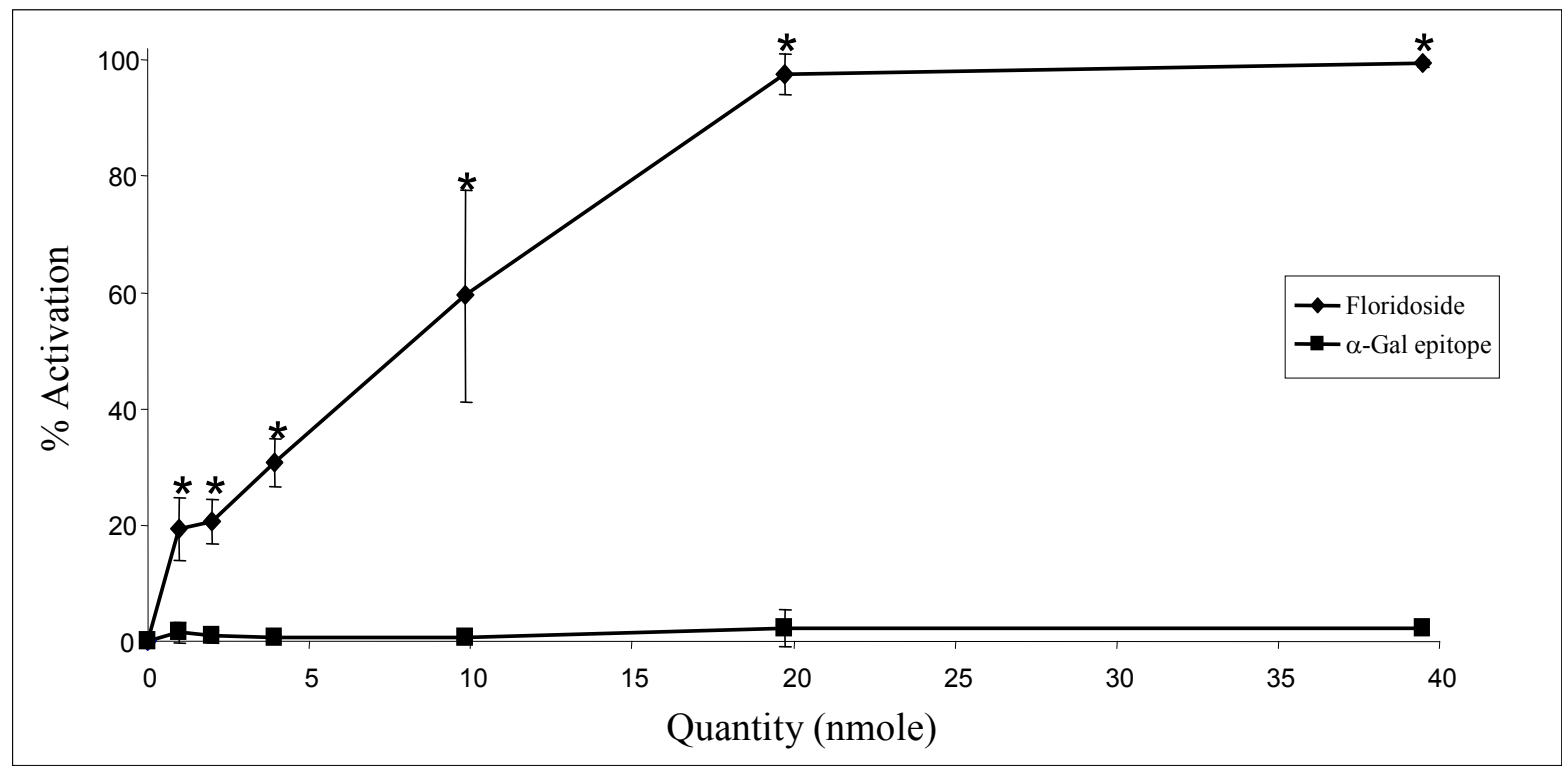

\section{Experimental}

\subsection{Materials}

Normal Human Serum (NHS) and Umbilical Serum (US) were obtained from healthy donors (National Blood Transfusion Service, Brest, France). Human complement C1q- and C2-deficient sera were purchased from Calbiochem (La Jolla, CA, USA). Guinea pig complement C4-deficient serum was purchased from Quidel (San Diego, USA). Sheep erythrocytes were commercially available (Eurobio, Paris, France). Rabbit anti-sheep erythrocytes antibodies were purchased from Biomerieux (Paris, France). ELISA C4d quantification kit was purchased from Quidel Corporation (San Diego, USA). Trisaccharide Gal $\alpha(1-3)$ Gal- $\beta(1-4)$ GlcNAc was ordered from Carbohydrate Synthesis (Oxford, UK). IgG was purchased from Roche (Paris, France).

\subsection{Buffers}

The following buffers were used: Phosphate Buffered Saline (PBS) 10 mM, pH 7.4; Veronal Buffer Saline $\left(\mathrm{VBS}^{2+}\right): 4 \mathrm{mM}$ veronal (Sigma-Aldrich, Saint-Quentin Fallavier, France), $0.15 \mathrm{mM} \mathrm{NaCl}$ (Sigma-Aldrich, Saint-Quentin Fallavier, France), $0.15 \mathrm{mM} \mathrm{Ca}^{2+}$ (Sigma-Aldrich, Saint-Quentin 
Fallavier, France), $0.5 \mathrm{mM} \mathrm{Mg}{ }^{2+}$ (Sigma-Aldrich, Saint-Quentin Fallavier, France), pH 7.3. Tris $\mathrm{HCl}$ Buffer $10 \mathrm{mM}, \mathrm{pH}$ 7.5. Citrate Buffer 0.1 M, pH 3.0.

\subsection{Extraction and isolation of floridoside}

Mastocarpus stellatus (Stackhouse) Guiry was harvested from the mid-sublittoral zone at Plouzané, in the Bay of Brest, France. Fresh material was washed with distilled water and frozen in liquid nitrogen. [Frozen] plant material (200 g) was ground in liquid nitrogen and then extracted with a mixture of 12:5:3 MeOH-C $\mathrm{CCl}_{3}-\mathrm{H}_{2} \mathrm{O}(400 \mathrm{~mL})$ for $1 \mathrm{~h}$ at room temperature. The hydroalcoholic phase was concentrated in a rotary evaporator, and then purified by passing it through successive columns of AG50 (200 mL, 20-50 mesh, X8, H , Biorad) and AG1 (200 mL, 20-50 mesh, X8, OH', Biorad). The neutral effluent was evaporated to dryness and redissolved in hot EtOH. White crystals of floridoside (500 mg) were obtained after partial evaporation of the alcoholic fraction.

3.4. Capacity of normal human serum to lyse $50 \%$ of sensitized erythrocytes through the classical pathway $\left(\mathrm{CH}_{50}\right.$ assay)

Antibody-sensitized sheep erythrocytes (AE) were prepared by incubating sheep erythrocytes with rabbit anti-sheep erythrocytes antibodies (Biomerieux, Paris, France) as described by Kazatchkine [19].

The $\mathrm{CH}_{50}$ represents the NHS concentration that leads to $50 \%$ AE lysis. To determine $\mathrm{CH}_{50}$, different concentrations of NHS $(800 \mu \mathrm{L})$, in $\mathrm{VBS}^{2+}$, were incubated with $200 \mu \mathrm{L}$ of AE at $10^{8}$ cells. $\mathrm{mL}^{-1}$ for 45 min at $37^{\circ} \mathrm{C}$. The controls corresponding to $0 \%\left(\mathrm{~L}_{0}\right)$ and $100 \%\left(\mathrm{~L}_{100}\right)$ lysis were obtained by incubation in the same conditions with $800 \mu \mathrm{L}$ of $\mathrm{VBS}^{2+}$ and $200 \mu \mathrm{L}$ of AE. After dilution in cold $0.15 \mathrm{M} \mathrm{NaCl}(2$ $\mathrm{mL}$ ) solution (except the one corresponding to the $\mathrm{L}_{100}$, where $2 \mathrm{~mL}$ of double distilled water (DDW) were added) and centrifugation, the residual $\mathrm{CH}_{50}$ units of the supernatants, corresponding to lysed EA hemoglobin, were determined by measuring the optical density (OD) at $414 \mathrm{~nm}$ (Uvikon, Serlabo, Bonneuil/Marne, France) [20].

\subsection{Hemolytic assay for evaluation of the classical complement pathway activation}

For the evaluation of the capacity of the floridoside to activate the complement system, various amounts of floridoside ( 0 to $100 \mu \mathrm{g}$ ) were pre-incubated with $15 \mu \mathrm{L}$ of NHS $\left(1 / 20\right.$ in $\mathrm{VBS}^{2+}$ ) for 45 min at $37^{\circ} \mathrm{C}$. Then, a mixture of $100 \mu \mathrm{L}$ of deficient serum in $\mathrm{C} 1 \mathrm{q}, \mathrm{C} 2$ or $\mathrm{C} 4$ proteins (whose dilution factor was previously determined to obtain $90 \%$ cell lysis in these experimental conditions) and 100 $\mu \mathrm{L}$ of $\mathrm{AE}$ at $10^{8}$ cells. $\mathrm{mL}^{-1}$ were added and incubated for another $45 \mathrm{~min}$ at $37^{\circ} \mathrm{C}$. The controls $\mathrm{L}_{0}$ and $\mathrm{L}_{100}$ were obtained as previously described. After dilution with cold $0.15 \mathrm{M} \mathrm{NaCl}(2 \mathrm{~mL})$ and centrifugation, the amount of the supernatant hemoglobin released was assessed by measuring OD at $414 \mathrm{~nm}$. A positive control for the reaction was obtained by incubation of aggregated IgG in the same experimental conditions [7]. For the comparison of the floridoside and the trisaccharide Gal $\alpha(1$ 3) Gal $\beta(1-4)$ GlcNAc activity, various concentrations of each molecule $(0-40 \mu \mathrm{mol})$ were treated under the same experimental conditions. 


\subsection{ELISA for the detection of complement activation products: Quantification of the C4d protein}

In order to evaluate complement activation by ELISA assays, the C4d protein production was measured. Briefly, various quantities of floridoside or aggregated $\operatorname{IgG}(0-100 \mu \mathrm{g})$ were incubated with NHS $\left(1 / 25\right.$ in $\left.\mathrm{VBS}^{2+}\right)$ for $45 \mathrm{~min}$ at $37^{\circ} \mathrm{C}$. The amount of $\mathrm{C} 4 \mathrm{~d}$ was quantified using the commercial kit from Quidel (San Diego, USA), which was used according to the manufacturer's instructions.

\subsection{Statistical analysis}

All results are expressed as means \pm standard error. Statistical differences between experimental groups were determined by ANOVA and individual means were compared with Student's $t$-test using InStat (GraphPad Software, San Diego, CA, USA). Values of $p<0.05$ were considered statistically significant.

\section{References}

1. Simon-Colin, C.; Kervarec, N.; Pichon, R.; Deslandes, E. Complete ${ }^{1} \mathrm{H}$ and ${ }^{13} \mathrm{C}$ spectral assignment of floridoside. Carbohydr. Res. 2002, 337(3), 279-80.

2. Simon-Colin, C.; Michaud, F.; Leger, J. M.; Deslandes, E. Crystal structure and chirality of natural floridoside. Carbohydr. Res. 2003, 338(22), 2413-6.

3. Putman, E. W.; Hassid, W. Z. Structure of galactosylglycerol from Iridea laminaroides. Biochem. J. 1954, 79, 7-12.

4. Galili, U.; Shohet, S. B.; Kobrin, E.; Stults, C. L.; Macher, B. A. Man, apes, and Old World monkeys differ from other mammals in the expression of alpha-galactosyl epitopes on nucleated cells. J. Biol. Chem. 1988, 263(33), 17755-62.

5. Walport, M. J. Complement. First of two parts. N. Engl. J. Med. 2001, 344(14), 1058-66.

6. Walport, M. J. Complement. Second of two parts. N. Engl. J. Med. 2001, 344(15), 1140-4.

7. Lutz, H. U.; Stammler, P.; Jelezarova, E.; Nater, M.; Spath, P. J. High doses of immunoglobulin G attenuate immune aggregate-mediated complement activation by enhancing physiologic cleavage of C3b in C3bn-IgG complexes. Blood 1996, 88(1), 184-93.

8. Brasher, G. W.; Hartley, T. F. Quantitation of IgA and IgM in umbilical cord serum of normal newborn infants. J. Pediatr. 1969, 74(5), 784-8.

9. Galili, U.; Basbaum, C. B.; Shohet, S. B.; Buehler, J.; Macher, B. A. Identification of erythrocyte Gal alpha 1-3Gal glycosphingolipids with a mouse monoclonal antibody, Gal-13. J. Biol. Chem. 1987, 262(10), 4683-8.

10. Thall, A.; Etienne-Decerf, J.; Winand, R. J.; Galili, U. The alpha-galactosyl epitope on human normal and autoimmune thyroid cells. Autoimmunity. 1991, 10(2), 81-7.

11. Galili, U. The alpha-gal epitope and the anti-Gal antibody in xenotransplantation and in cancer immunotherapy. Immunol. Cell. Biol. 2005, 83(6), 674-86.

12. Galili, U.; Rachmilewitz, E. A.; Peleg, A.; Flechner, I. A unique natural human IgG antibody with anti-alpha-galactosyl specificity. J. Exp. Med. 1984, 160(5), 1519-31. 
13. Galili, U.; Macher, B. A.; Buehler, J.; Shohet, S. B. Human natural anti-alpha-galactosyl IgG. II. The specific recognition of alpha $(1 \rightarrow 3)$-linked galactose residues. J. Exp. Med. 1985, 162(2), 573-82.

14. Galili, U. Interaction of the natural anti-Gal antibody with alpha-galactosyl epitopes: a major obstacle for xenotransplantation in humans. Immunol. Today 1993, 14(10), 480-2.

15. Rieben, R.; Bovin, N. V.; Korchagina, E. Y.; Oriol, R.; Nifant'ev, N. E.; Tsvetkov, D. E.; Daha, M.R.; Mohacsi, P. J.; Joziasse, D. H. Xenotransplantation: in vitro analysis of synthetic alphagalactosyl inhibitors of human anti-Galalpha1 $\rightarrow 3 \mathrm{Gal}$ IgM and IgG antibodies. Glycobiol. 2000, 10(2), 141-8.

16. Morgan, B. P.; Harris, C. L. Complement therapeutics; history and current progress. Mol. Immunol. 2003, 40(2-4), 159-70.

17. Edens, R. E.; Linhardt, R. J.; Bell, C. S.; Weiler, J. M. Heparin and derivatized heparin inhibit zymosan and cobra venom factor activation of complement in serum. Immunopharmacol. 1994, 27(2), 145-53.

18. Trail, P. A.; Bianchi, A. B. Monoclonal antibody drug conjugates in the treatment of cancer. Curr. Opin. Immunol. 1999, 11(5), 584-8.

19. Kazatchkine, M.; Hauptmann, G.; Nydegger, U. Dosages hémolytiques des composants du Complément; Société française d'Immunologie: Paris, France, 1985; pp. 15-44.

20. Blondin, C.; Chaubet, F.; Nardella, A.; Sinquin, C.; Jozefonvicz, J. Relationships between chemical characteristics and anticomplementary activity of fucans. Biomaterials 1996, 17(6), 597 603.

Sample Availability: Available from the authors

(C) 2008 by the authors; licensee Molecular Diversity Preservation International, Basel, Switzerland. This article is an open-access article distributed under the terms and conditions of the Creative Commons Attribution license (http://creativecommons.org/licenses/by/3.0/). 